\title{
Efeitos de substratos na qualidade de mudas pré-brotadas de cana-de-açúcar
}

\author{
Effects of substrates on the quality of sugarcane pre-sprouted \\ seedlings
}

Bruno Nicchio $^{1 *}$, Clayton Caramello Cardozo², Marlon Anderson Marcondes Vieira ${ }^{1}$

Universidade Federal de Uberlândia (UFU), R. Acre, 1004, Umuarama, CEP 38405-325, Uberlândia, MG, Brasil ${ }^{2}$ Centro Universitário Presidente Antônio Carlos (UNIPAC), Uberlândia, MG, Brasil.

*autor correspondente \bruno_nicchio@hotmail.com
RESUMO: Um dos maiores desafios nas áreas comerciais de produção de cana-de-açúcar é a qualidade do talhão após o plantio, já que as falhas podem representar redução de produtividade. A utilização de mudas pré-brotadas (MPB) pode auxiliar no manejo de correção de talhão e aumentar a eficiência na implantação de viveiros (cana para semente). Contudo, melhorar o desenvolvimento de mudas com substratos mais eficientes é de grande importância. Deste modo, o objetivo deste trabalho foi avaliar o efeito de substratos na qualidade de mudas pré-brotadas de cana-de-açúcar. O experimento foi conduzido em viveiro localizado na Bioenergética Aroeira e apresentou delineamento experimental inteiramente casualizado, sendo quatro substratos (Padrão, Bioflora, Vivatto e VigorFert), com cinco repetições. Foi avaliada a altura da plântula, massa fresca da parte aérea, IVE e emergência acumulada de MPB. Os resultados deste estudo demonstraram que o uso do substrato VigorFert apresentou resultados mais satisfatórios para massa fresca da parte aérea, porcentagem de emergência e índice de velocidade de emergência de mudas pré-brotadas de cana-de-açúcar. O substrato Vivatto apresentou melhores resultados que o padrão usina e Bioflora para produção de massa fresca da parte aérea de mudas pré-brotadas de cana-de-açúcar.

PALAVRAS-CHAVE: MPB, resíduos, Saccharum officinarum L.
ABSTRACT: One of the biggest challenges in the commercial sugarcane production areas is the quality of the area after planting, since failures can lead to reduced productivity. The use of pre-sprouted seedlings (PSS) can assist in the management of field correction and increase efficiency in the implantation of nurseries (cane for seed). However, improving the development of seedlings with more efficient substrates is of great importance. Thus, the objective of this study was to evaluate the effect of substrates on the quality of pre-sprouted sugarcane seedlings. The experiment was conducted in a completely randomized design, with four substrates (Standard, Bioflora, Vivatto and Vigorfert), with five replications. Seedling height, fresh shoot weight, IVE and accumulated PSS emergence were evaluated. The results of this study demonstrated that the use of the substrate Vigorfert showed more satisfactory results for fresh mass of the aerial part, percentage of emergence and index of emergence speed of pre-sprouted sugarcane seedlings. The Vivatto substrate showed better results than the standard and Bioflora for the production of fresh mass from the aerial part of pre-sprouted sugarcane seedlings.

KEYWORDS: PSS, waste, Saccharum officinarum L.

\section{Introdução}

A cana-de-açúcar é uma cultura semiperene que possibilita vários cortes sem necessidade de plantio, e em lavouras comerciais sua propagação ocorre de maneira vegetativa, ou seja, a partir dos toletes (parte do colmo que contém as gemas) de forma assexuada (PINTO et al., 2016; JESUS et al., 2019). A estimativa para a safra 2019/2020 é de 622,3 milhões de toneladas, representando um acréscimo de $0,3 \%$ em relação à safra anterior. A produção estimada de etanol é de 30,3 bilhões de litros, e a produção estimada de açúcar deverá atingir 31,8 milhões de toneladas. Quanto à 
área colhida, por sua vez, estima-se 8,38 milhões de hectares, o que implica retração de $2,4 \%$, se comparado ao ano anterior (COMPANHIA NACIONAL DEABASTECIMENTO, 2019).

A partir do plantio mecanizado dos canaviais, é comum observar-se falhas nas linhas de plantio. Em condições favoráveis, a gema pode se desenvolver, mas caso não encontre condições favoráveis, a gema pode não brotar, acarretando falhas no canavial, o que pode reduzir ganho e produção por área (OLIVEIRA et al., 2018). Percebendo este problema, o Instituto Agronômico de Campinas desenvolveu um método de plantio através de mudas pré-brotadas (MPB) de cana-de-açúcar, provenientes de gemas individualizadas. O sistema MPB permite alcançar aumento de eficiência e ganho econômico na implantação de viveiros, replantio de áreas comerciais, expansão e renovação de áreas plantadas de cana-de-açúcar (PINTO et al., 2016; DE MARCO et al., 2017; BRAGA et al., 2019; JESUS et al., 2019).

No sistema convencional, é necessário o consumo de aproximadamente 18 a 20 toneladas de mudas para que seja plantado um hectare de cana. Enquanto isso, se colocado em ação o sistema de tecnologia de MPB, tal quantidade diminui para até 2 toneladas (DE MARCO et al., 2017; GOMES, 2018; OLIVEIRA et al., 2018). As mudas pré-brotadas (MPB) configuram um sistema utilizado na produção da cana-de-açúcar, cujo objetivo é a multiplicação rápida de mudas, que deve estar associada a um padrão de fitossanidade, além de vigor e uniformidade do plantio. Esta tecnologia implica, ainda, não só a produção com um custo mais baixo, mas também a diminuição do uso de matéria-prima (PINTO et al., 2016; JESUS et al., 2019; REIS et al., 2019).

Durante a produção das mudas, o substrato utilizado é um dos fatores de maior influência no crescimento destas, podendo apresentar vantagens, mas também desvantagens, em função principalmente da espécie vegetal em que se está trabalhando, que pode levar ou não à diminuição de seu tempo no viveiro, o que pode diminuir o custo de produção (ORTOLAN; SEGATO, 2014; DE MARCO et al., 2017).

Enquanto o solo possui valores fixos quanto ao seu potencial produtivo, os substratos, quando bem formulados, permitem melhores condições ao desenvolvimento vegetal, especialmente em cultivos protegidos (JAEGGI et al., 2016). Desta maneira, formar mudas com qualidade é fundamental, em função da influência na percentagem de sobrevivência, na velocidade e na qualidade de crescimento e na produção final da cana-de-açúcar, além de exercer melhor controle da vegetação invasora e reduzir os custos dos tratos culturais (GAZOLA; CIPOLA FILHO; FRANCO JÚNIOR, 2017; BRAGA et al.,, 2019).

O substrato influencia bastante no desenvolvimento e na aclimatização das mudas através de suas características físicas, químicas e biológicas, podendo ser considerado um bom substrato aquele que proporciona boas condições de umidade, teor de nutrientes, disponibilidade de nutrientes e de água, macro e microporosidade, capacidade de troca de cátions, boa regeneração às raízes e uniformidade (BARRETO et al., 2018; NORONHA et al., 2018).

Os substratos podem ser diferenciados como orgânicos ou minerais quimicamente ativos ou inertes (PINTO et al., 2016).
Os materiais orgânicos têm origem em resíduos vegetais que se decompõem e podem ser quimicamente ativos, podendo adsorver ou liberar nutrientes para o meio. Os materiais mais comumente utilizados são: turfa, cascas de árvores (pinus), fibra de coco, casca de arroz, vermiculita, areia lavada e substrato comercial (BARRETO et al., 2018). Por outro lado, os minerais, mais comuns, são provenientes de materiais quimicamente inativos ou inertes, como perlita, espuma fenólica, lã de rocha e argila expandida (com exceção da vermiculita, que possui elevada capacidade de troca de cátions).

Contudo, faz-se necessário o estudo visando encontrar melhores fontes de substratos para que o sistema de propagação de MPB de cana-de-açúcar seja conduzido de forma sustentável, haja vista que se trata de uma tecnologia recente e com poucos estudos voltados para o correto manejo da fertilidade (GAZOLA; CIPOLA FILHO; FRANCO JÚNIOR, 2017). Desta forma, se combinada com a produção de mudas pré-brotadas, a utilização de substratos é capaz de resultar em uma produção da cultura cujo índice de qualidade seja visivelmente maior. Portanto, o objetivo deste estudo foi avaliar o efeito de substratos na qualidade de mudas pré-brotadas de cana-de-açúcar.

\section{Material e Métodos}

O experimento foi realizado em um viveiro de multiplicação de mudas pré-brotadas (MPB) pertencentes à Bioenergética Aroeira, localizada em Tupaciguara, Minas Gerais, nas coordenadas $18^{\circ} 45^{\prime} 14^{\prime \prime} \mathrm{S} 48^{\circ} 36^{\prime} 43^{\prime \prime} \mathrm{W}$. O estudo foi realizado durante o período de abril a maio de 2019 . O clima da região, de acordo com a classificação climática Koppen-Geiger, enquadra-se como tropical de altitude.

$\mathrm{O}$ delineamento experimental utilizado foi inteiramente casualizado (DIC), com quatro tratamentos e cinco repetições. Os tratamentos consistiram no uso de diferentes tipos de substratos, sendo: Substrato Padrão da indústria canavieira ( $50 \%$ de bagaço de cana $+40 \%$ de fuligem da usina $+10 \%$ de torta de filtro); Bioflora (substrato comercial composto por casca de pinus + fibras naturais + fertilizante mineral); Vivatto (substrato comercial composto por casca de pinus bioestabilizada + vermiculita + moinha de carvão vegetal + água + espuma fenólica); VigorFert (substrato comercial composto por carbono orgânico + esterco e camas de aviário + cinzas + palha de milho).

As mudas utilizadas neste estudo foram provenientes do plantio de gemas de cana-de-açúcar, variedade RB 98-8082, cortadas em modelo minirrebolos (3-4 cm) extraídas a partir da guilhotina. A semeadura foi realizada em bandejas de PVC com capacidade de 50 células, com uma gema por cédula. Cada repetição constitui-se de duas bandejas de PVC, nas quais foram dispostos os substratos antes do plantio das gemas. Durante a condução do experimento foram realizadas irrigações diárias (quatro vezes ao dia), pois as bandejas foram dispostas em local aberto em talhões de arame colocados diretamente no chão.

O experimento foi conduzido por um período total de 40 dias após o plantio, em que foram avaliadas: emergência de mudas aos 10, 20, 30 e 40 dias após a emergência; altura 
(cm) de 10 mudas amostradas aleatoriamente em cada parcela (bandeja) com auxílio de trena; massa fresca da parte aérea $\left(\mathrm{g}\right.$ planta $\left.{ }^{-1}\right)$ utilizando-se balança de precisão $(0,001 \mathrm{~g})$ em 10 mudas amostradas aleatoriamente em cada parcela (bandeja), totalizando 50 plantas amostradas por tratamento.

Também aos 40 dias após o tratamento de rebolos e plantio foi realizada avaliação do índice de velocidade de emergência (IVE), porcentagem e pico de emergência de MPB. Após obtenção destes dados, foi realizado o cálculo para porcentagem de emergência, pela fórmula proposta nas Regras para Análise de Sementes (BRASIL, 2009):

$G=\frac{N G \times 100}{N T}$

Em que:

$\mathrm{NG}=$ número de gemas emergidas; e

$\mathrm{NT}=$ número de gemas colocadas para germinar.

Além disso, calculou-se o índice de velocidade de emergência (IVE) conforme fórmula proposta por Maguire (1962):

$I V e=\sum \frac{N G i}{T i}$

Em que:

$\mathrm{NGi}$ = número de gemas emergidas no dia i; e

$\mathrm{Ti}$ = tempo, em dias, após a semeadura, para a emergência.

Posteriormente à obtenção dos dados, estes foram submetidos à análise de variância pelo teste de $\mathrm{F}$, e em caso de significância, as médias foram comparadas por meio do Teste de Tukey, ambas 0,05 de significância, com auxílio do programa de análises estatísticas Sisvar ${ }^{\mathbb{R}}$ (FERREIRA, 2014).

\section{Resultados e Discussão}

Os resultados para médias de altura $(\mathrm{cm})$ e massa fresca da parte aérea (MFPA) de mudas pré-brotadas em cana-de-açúcar encontram-se na Tabela 1. Aos 40 dias após o plantio, observou-se que não houve diferença significativa para altura de plantas entre os tratamentos avaliados, com média geral de $36 \mathrm{~cm}$.

Esses resultados se assemelham aos de Pinto et al. (2016) ao avaliarem a influência de diferentes substratos (Bioplant, $50 \%$ substrato comercial $+50 \%$ terra de subsolo, $50 \%$ terra de subsolo $+50 \%$ torta de filtro e $50 \%$ substrato comercial $+50 \%$ torta de filtro) na produção de MPB aos 50 dias após o plantio. Os autores não observaram diferença entre os tratamentos avaliados.

Por outro lado, Braga (2016) verificou influência na altura de MPB em função da utilização de diferentes substratos, com mudas atingindo mais de $30 \mathrm{~cm}$ após 30 dias. Além disso, Ohashi et al. (2016) e Garcia et al. (2016) obtiveram MPB com médias de $20 \mathrm{~cm}$ de altura com substrato comercial, e $25 \mathrm{~cm}$ com substrato à base de casca de pinus e vermiculita, aos 60 e 56 dias após o plantio, respectivamente.

Santi et al. (2016) observaram maior altura de MPB (variedades RB 96-6928, RB 86-7515 e RB 92-579) aos 70 dias após plantio com uso de substratos comerciais (mistura de fonte orgânica, química e areia) em comparação com tratamento areia e areia + solução nutritiva. De Marco et al. (2017) observaram maior altura de MPB (variedade RB 97-5932) com tratamento proveniente de Turfa Fértil em comparação com tratamento proveniente de $50 \%$ substrato orgânico $+45 \%$ casca de arroz $+5 \%$ torta de tungue aos 45 dias após o plantio. Lemoes et al. (2017) observaram que os substratos com maiores proporções de casca de arroz carbonizada e composto orgânico proporcionam o melhor crescimento e desenvolvimento de MPB (variedades RB 86-7515 e RB 96-6928).

Barreto et al. (2018), ao avaliarem diferentes tipos de substratos na produção de MPB, observaram melhores resultados com substratos misturados com torta de filtro, vermiculita, areia e terra turfosa, com médias de altura entre 73,6 e 75,9 cm de MPB (variedade RB 92-579). Jesus et al. (2019), ao avaliarem tipos de substratos (substrato comercial; substrato comercial + esterco bovino; e, esterco bovino + areia lavada) na produção de MPB, verificaram que, independentemente do substrato, houve aumento na altura e diâmetro de mudas aos 55 dias após o plantio.

É importante a avaliação de características biométricas (altura e diâmetro), pois o potencial de acúmulo de sacarose por plantas de cana está relacionado quanto a estes parâmetros na fase inicial da muda (SANTI et al., 2016). As diversas características morfológicas dos colmos e suas gemas são imbuídas a cada genótipo, e estas são responsáveis pela ampla variabilidade de comportamento das mudas de cana-de-açúcar. O sistema MPB tende a reduzir o peso "negativo" dessas características porque individualiza um pequeno segmento do colmo e o trata de maneira favorável para a brotação, pois estabelece condições controladas para tal (XAVIER; LANDELL; CAMPANA, 2014). A brotação e o desenvolvimento inicial de gemas de cana-de-açúcar sofrem a influência de diversos fatores, entre eles o substrato, ou seja, o meio no qual os minitoletes são colocados para brotar, bem como o fator nutricional (DE MARCO et al., 2017).

Com relação à massa fresca da parte aérea (MFPA), o substrato comercial VigorFert (carbono orgânico + esterco e camas de aviário + cinzas + palha de milho) foi mais eficiente $\left(161,2 \mathrm{~g}\right.$ planta $\left.^{-1}\right)$ que o substrato Padrão ( $50 \%$ de bagaço $+40 \%$ de fuligem $+10 \%$ de torta de filtro) e Bioflora (substrato comercial composto por casca de pinus + fibras naturais + fertilizante mineral), com incrementos de 8,0 e 9,0 g planta $^{-1}$, respectivamente (Tabela 1). Já o substrato Vivatto (substrato comercial composto por casca de pinus bioestabilizada + vermiculita + moinha de carvão vegetal + água + espuma fenólica) não diferiu estatisticamente dos demais.

Santi et al. (2016) observaram maior MFPA de MPB (variedades RB 96-6928, RB 86-7515 e RB 92-579) aos 70 dias

Tabela 1. Médias de altura (cm) e massa fresca da parte aérea (MFPA) de mudas pré-brotadas em cana-de-açúcar em função do uso de diferentes substratos.

\begin{tabular}{|c|c|c|}
\hline Substrato* & Altura (cm) & MFPA (g planta $\left.{ }^{-1}\right)$ \\
\hline Padrão & 36,0 a & $153,2 \mathrm{~b}$ \\
\hline Bioflora & 36,2 a & $152,2 \mathrm{~b}$ \\
\hline Vivatto & 36,1 a & $154,4 \mathrm{ab}$ \\
\hline VigorFert & 35,7 a & 161,2 a \\
\hline Médias & 36,0 & 155,2 \\
\hline
\end{tabular}

*Médias seguidas por letras distintas na coluna diferem entre si pelo teste de Tukey a 0,05 de significância. 
após plantio com uso de substratos comerciais (mistura de fonte orgânica, química e areia) em comparação com tratamento areia e areia + solução nutritiva. Garcia et al. (2016) também observaram diferença entre massa seca da parte aérea (MSPA) de MPB produzidas em diferentes substratos aos 35 dias após plantio, com a maior média obtida com substrato padrão à base de casca de pinus e fibra de coco (129 $\left.\mathrm{g} \mathrm{planta}^{-1}\right)$. Pinto et al. (2016) encontraram maior produção de MSPA com tratamento composto por $50 \%$ substrato comercial $+50 \%$ terra de subsolo em comparação ao substrato comercial. Barreto et al. (2018) observaram melhores resultados de MSPA com tratamentos provenientes de substratos misturados com torta de filtro e terra turfosa, além de substrato comercial.

Gazola, Cipola Filho e Franco Júnior (2017), ao avaliarem qualidade de mudas formadas em diferentes substratos, observaram maior produção de MSPA com substrato com $31 \%$ de esfagno $+10 \%$ de vermiculita, $9 \%$ de casca de arroz carbonizada $+300 \mathrm{~g}$ de sulfato de amônio $+200 \mathrm{~g}$ de $\mathrm{KCl}+200 \mathrm{~g}$ de termofosfato $+500 \mathrm{~g}$ de Basacote aos 35 , 49 e 64 dias após o plantio. Braga et al. (2019), ao avaliarem substratos comerciais (TRIMIX: casca de arroz, vermiculita e fibra de coco; BIOPLANT®: casca de pinheiro, fibra de coco, vermiculita e nutrientes) em comparação com resíduos da agroindústria (bagaço de cana + torta de filtro; e bagaço de cana + torta de filtro + areia), observaram maior produção de MSPA de MPB com os substratos comerciais.

Neste estudo, os substratos mais satisfatórios são aqueles com composição de material mais completa, como esterco de aviário, palha de milho, casca de pinus bioestabilizada e vermiculita. Substratos com materiais que favoreçam maior retenção de água (através de cascas, palhas e vermiculita) e disponibilidade de nutrientes (através de compostos orgânicos, esterco de aviário e composto bioestabilizado), podem apresentar maior eficiência. O substrato é fundamental na formação e qualidade das mudas, pois deve permitir o funcionamento adequado do sistema radicular e suprir os requisitos nutricionais necessários ao desenvolvimento inicial da planta em condições de campo (JESUS et al., 2019). Este fato é de extrema importância, quando considerado que a época de plantio da cana na região centro-sul do país é feita nos meses de fevereiro e março, caracterizada pelo final da estação chuvosa (BRAGA et al., 2019).

A avaliação sobre porcentagem de emergência (E\%) e índice de velocidade de emergência (IVE) mostrou que o substrato VigorFert $(81,4 \%$ e 3,89$)$ apresentou melhores resultados que o substrato Bioflora $(24,8 \%$ e 1,17$)$ (Tabela 2). De Marco et al. (2017) observaram maior IVE de MPB (variedade RB 97-5932) com tratamento proveniente de turfa fértil em comparação com tratamento proveniente de $50 \%$ substrato orgânico $+45 \%$ casca de arroz $+5 \%$ torta de tungue aos 45 dias após o plantio. Gazola, Cipola Filho e Franco Júnior (2017) também observaram maior desenvolvimento de brotações com adubação orgânica. O substrato VigorFert provavelmente foi mais eficiente em disponibilizar nutrientes e água para as mudas, em função de sua composição com composto orgânico e cama de aviário (rico em nutrientes como N). Por outro lado, o Bioflora, substrato com resultados mais baixos, composto por palha de milho e casca de pinus, o que pode ter reduzido a eficiência do fertilizante mineral na composição associada a maior perda de água por lixiviação.

$\mathrm{O}$ tratamento com Vivatto apresentou resultados semelhantes aos do VigorFert para E\% e IVE (Tabela 2). Mesmo contendo casca de pinus em sua composição, o Vivatto produto contém vermiculita (uniformidade na composição química e granulométrica, porosidade e capacidade de retenção de água), o que pode ajudar na retenção de umidade, e em associação com material orgânico favorece maior disponibilidade de nutrientes (MARTINS; BOVI; SPIERING, 2009; GAZOLA; CIPOLA FILHO; FRANCO JÚNIOR, 2017). O padrão da usina também apresentou resultados intermediários para $\mathrm{E} \%$ $(64,2 \%)$ e IVE $(3,19)$. Esta fonte possui capacidade de retenção de água em função do material presente em sua composição (torta de filtro e bagaço de cana), mas de acordo com Gazola, Cipola Filho e Franco Júnior (2017), o bagaço de cana e a torta de filtro podem não garantir o suprimento de todos os nutrientes necessários para o máximo desenvolvimento das mudas, havendo, portanto, a necessidade de suplementar com fertilizantes químicos.

Apesar de os autores observarem melhores resultados nas variáveis analisadas com substrato comercial, sua utilização pode onerar o custo de produção de muda (AFERRI; XAVIER; PEREIRA, 2016; BARRETO et al., 2018). Por isso, o uso de resíduos orgânicos na forma de substratos para a produção de mudas é uma maneira viável de reduzir os custos de um sistema de produção, e assim como observado nos resultados abordados deste estudo, onde a mistura de resíduos orgânicos a fontes minerais na composição de substrato (VigorFert: substrato comercial composto por carbono orgânico + esterco e camas de aviário + cinzas + palha de milho) pode beneficiar a reciclagem de nutrientes, tornando o sistema agrícola mais sustentável em função de as fontes serem mais eficientes e ricas em nutrientes e em matéria orgânica (JESUS et al., 2019).

De acordo com a Figura 1, o pico de emergência de MPB em cada tratamento pode ser observado entre os 20 e 40 dias após o plantio, mas apenas o substrato Padrão apresentou uma leve redução após os 20 primeiros dias de plantio, com um aumento entre o $30^{\circ}$ e o $40^{\circ}$ dia após o plantio.

No geral, o substrato Bioflora (casca de pinus + fibras naturais + fertilizante mineral) apresentou resultados mais baixos (Figura 1). Existem várias limitações que podem ser apresentadas pelos substratos comerciais, como o crescimento desuniforme de mudas em função da compostagem imperfeita

Tabela 2. Médias para emergência (E) e índice de velocidade de emergência (IVE) de mudas pré-brotadas em cana-de-açúcar em função do uso de diferentes substratos.

\begin{tabular}{cll}
\hline Substrato* & E $(\%)$ & IVE \\
\hline Padrão Usina & 64,2 ab & 3,19 ab \\
Bioflora & $24,8 \mathrm{~b}$ & $1,17 \mathrm{~b}$ \\
Vivatto & 59,0 ab & $2,87 \mathrm{ab}$ \\
VigorFert & $\mathbf{8 1 , 4} \mathrm{a}$ & 3,89 a \\
Médias & 57,3 & 2,78 \\
\hline
\end{tabular}

*Médias seguidas por letras distintas na coluna diferem entre si pelo teste de Tukey a 0,05 de significância. 


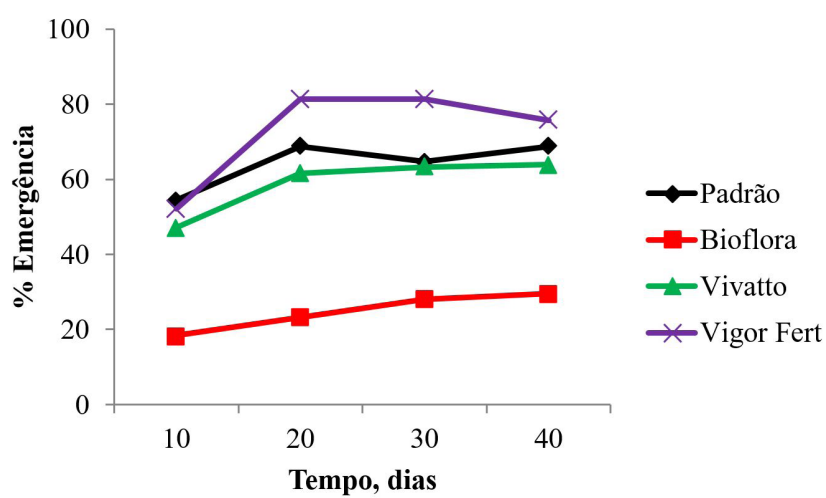

Figura 1. Emergência acumulada (\%) de mudas pré-brotadas (MPB) de cana-de-açúcar (variedade RB 98-8082) durante 40 dias após o plantio em função do uso de diferentes substratos.

da casca de pinus e excessivamente ricos em nutrientes, uma vez que os sais solúveis podem provocar necrose e queima das raízes (XAVIER; LANDELL; CAMPANA, 2014; BRAGA et al., 2019).

Gazola, Cipola Filho e Franco Júnior (2017), em experimento visando avaliar melhores substratos para produção de MPB, verificaram que a complexa interação entre variedade de cana-de-açúcar e os substratos de produção de mudas, associada à variabilidade experimental, não permitiu a avaliação mais conclusiva sobre o melhor produto. De acordo com os autores, o sistema de produção de MPB é uma técnica recente e, naturalmente, ainda existem lacunas nas pesquisas que precisam ser esclarecidas. Não se sabe ao certo quais nutrientes e formas de aplicação devem ser realizadas durante o período de produção das MPBs. Além disso, faltam informações quanto às características físico-químicas dos resíduos/compostos utilizados na produção dos substratos para produção de mudas, o que dificulta ainda mais a obtenção destas informações (GAZOLA; CIPOLA FILHO; FRANCO JÚNIOR, 2017).

Embora tenham sido detectadas diferenças no desenvolvimento de MPB produzidas em diferentes substratos, é necessário avaliar seu desempenho em condições de campo. Isso porque as mudas são sujeitas a fatores bióticos e abióticos que podem potencializar ou mesmo neutralizar os efeitos obtidos em viveiros (BRAGA et al., 2019). Por isso, torna-se necessário explorar este sistema de produção de MPB para obtenção de mais informações quanto aos requisitos de produção e características nutricionais dos principais genótipos (BRAGA et al., 2019; JESUS et al., 2019).

\section{CONCLUSÕES}

O substrato VigorFert (composto por carbono orgânico + esterco e camas de aviário + cinzas + palha de milho) foi mais eficiente que os demais substratos (Padrão, Bioflora e Vivatto) para massa fresca da parte aérea, porcentagem de emergência e índice de velocidade de emergência de mudas pré-brotadas de cana-de-açúcar. O substrato Vivatto demonstrou resultados intermediários quanto aos demais substrato na produção de mudas pré-brotadas de cana-de-açúcar.

\section{REFERÊNCIAS}

AFERRI, G.; XAVIER, M. A.; PEREIRA, M. A. A. Custo de produção de mudas pré-brotadas de cana-de-açúcar - MPB. Pesquisa \& Tecnologia, Campinas, v. 13, n. 2, p. 1-5, 2016.

BARRETO, M. C. et al. Aclimatização de mudas pré-brotadas de cana-de-açúcar em diferentes substratos. In: AMORMINO JÚNIOR, M. (Ed.). Elementos da natureza e propriedades do solo. Ponta Grossa: Atena Editora. 2018. p. 8-16.

BRAGA, N. C. C. et al. Production of sugarcane seedlings pre-sprouted in comercial and alternative substrates with by-products of the sugarcane industry. Semina: Ciências Agrárias, Londrina, v. 40, n. 1, p. 33-48, 2019. http://dx.doi.org/10.5433/1679-0359.2019v40n1p33.

BRAGA, N. C. C. Produção de mudas pré-brotadas de cana-deaçúcar em substratos comerciais e alternativos com subprodutos da indústria canavieira. 2016. $50 \mathrm{f}$. Dissertação (Mestrado em Ciências Agrárias - Agronomia) - Instituto Federal Goiano, Campus Rio Verde, Rio Verde, 2016.

BRASIL. Ministério da Agricultura, Pecuária e Abastecimento. Regras para análise de sementes. Brasília: SDA/ACS, 2009. 399 p.

COMPANHIA NACIONAL DE ABASTECIMENTO - CONAB. Acompanhamento da safra brasileira de cana-de-açúcar: segundo levantamento. Brasília: CONAB, 2019. v. 6, 58 p.

DE MARCO, E. et al. Uso de substratos alternativos na produção de mudas de cana-de-açúcar. Revista da Jornada da Pós-graduação e Pesquisa Congrega URCAMP, Bagé, v. 1, p. 2677-2690, 2017.

FERREIRA, D. F. Sisvar: a Guide for its Bootstrap procedures in multiple comparisons. Ciência Agrotecnologia, Lavras, v. 38, n. 2, p. 109-112, 2014.

GARCIA, J. C. et al. Fertilizantes de liberação controlada na formação de mudas pré-brotadas de cana-de-açúcar. In: CONGRESSO NACIONAL DA SOCIEDADE DOS TÉCNICOS AÇUCAREIROS E ALCOOLEIROS DO BRASIL, 10., 2016, Ribeirão Preto. Anais... Ribeirão Preto: STAB, 2016. p. 241-244.

GAZOLA, T.; CIPOLA FILHO, M. L.; FRANCO JÚNIOR, N. C. Avaliação de mudas pré-brotadas de cana-de-açúcar provenientes de substratos submetidos a adubação química e orgânica. Científica (Jaboticabal), Jaboticabal, v. 45, n. 3, p. 300-306, 2017. http:// dx.doi.org/10.15361/1984-5529.2017v45n3p300-306.

GOMES, C. IAC desenvolve sistema inédito que muda o conceito de plantar cana: dentre os benefícios estão redução do número de mudas e possibilidade de aumento dos ganhos do produtor. Campinas: Instituto Agronômico de Campinas, 2018. Disponível em: <http:// www.iac.sp.gov.br/noticiasdetalhes.php?id=836>. Acesso em: 5 abr. 2019.

JAEGGI, M. E. P. C. et al. Desenvolvimento vegetativo de mudas de rabanete em diferentes substratos orgânicos. In: SEMINÁRIO DE AGROECOlOGIA DO SUL, 2., 2016, Dourados. Anais... Dourados, MS: EMBRAPA, 2016.

JESUS, H. I. et al. Development and gas Exchange of pre-sprouted sugarcane seedlings in three diferente growing substrate media. Journal of Experimental Agriculture International, Hooghly, v. 32, n. 4, p. 1-7, 2019. http://dx.doi.org/10.9734/jeai/2019/ v32i430114.

LEMOES, L. S. et al. Crescimento e desenvolvimento de mudas de cana-de-açúcar em diferentes substratos. Revista da Jornada da Pós-graduação e Pesquisa Congrega URCAMP, Bagé, v. 1, p. 465-476, 2017.

MAGUIRE, J. D. Speed of germination-aid in selection and evaluation for seedling emergence and vigor. Crop Science, 
Madison, v. 2, n. 1, p. 176-177, 1962. http://dx.doi.org/10.2135/ cropsci1962.0011183X000200020033x.

MARTINS, C. C.; BOVI, M. L. A.; SPIERING, S. H. Umedecimento do substrato na emergência e vigor de plântulas de pupunheira. Revista Brasileira de Fruticultura, Jaboticabal, v. 31, n. 1, p. 224-230, 2009

NORONHA, R. H. F. Plantio de mudas pré-brotadas (MPB) de cana de açúcar em sistemas de manejo conservacionista de solo. 2018. 78 f. Tese (Doutorado em Agronomia) - Universidade Estadual Paulista, Faculdade de Ciências Agrárias e Veterinárias, Jaboticabal, 2018.

OHASHI, A. Y. P. et al. Crescimento e eficiência no uso da água de mudas pré-brotadas de cana-de-açúcar em diferentes substratos. In: CONGRESSO NACIONAL DA SOCIEDADE DOS TÉCNICOS AÇUCAREIROS E ALCOOLEIROS DO BRASIL, 10., 2016, Ribeirão Preto. Anais... Ribeirão Preto: STAB, 2016. p. 212-216.

OLIVEIRA, H. P. et al. Performance of pre-sprouted sugarcane seedlings in response to the application of humic acid and plant growth-promoting bactéria. Semina: Ciências Agrárias, Londrina, v. 39, n. 3, p. 1365-1370, 2018. http://dx.doi.org/10.5433/1679$0359.2018 \mathrm{v} 39 \mathrm{n} 3 \mathrm{p} 1365$.

ORTOLAN, M. A.; SEGATO, S. V. Massa seca de mudas pré-brotadas de cana-de-açúcar em tubete em função da dose do adubo foliar. Nucleus, Ituverava, v. 11, n. 2, p. 1311, 2014.

PINTO, L. E. V. et al. Produção de mudas pré-brotadas de cana-deaçúcar em função de diferentes substratos. Colloquium Agrariae, Presidente Prudente, v. 12, p. 93-99, 2016. Número especial http:// dx.doi.org/10.5747/ca.2016.v12.nesp.000177

REIS, G. V. et al. Growth response of pre-sprouted seedlings of sugarcane in the presence of the bacterium Herbarspirillum frisingense. International Journal of Environment, Agricultural Biotechnology, India, v. 4, n. 5, p. 1387-1391, 2019. http://dx.doi. org/10.22161/ijeab.45.15.

SANTI, P. H. P. et al. Desenvolvimento de mudas pré-brotadas (MPB) de cana-de-açúcar em diferentes substratos. In: WORSHOP AGROENERGIA MATÉRIAS-PRIMAS, 10., 2016, Ribeirão Preto. Anais... Ribeirão Preto: IAC, 2016. 7p.

XAVIER, M. A.; LANDELL, M. G.; CAMPANA, M. P. Fatores de desuniformidade e kit de pré-brotação IAC para sistema de multiplicação de cana-de-açúcar - mudas pré-brotadas (MPB). Campinas: IAC, 2014. 22 p. (Documentos, n. ${ }^{\circ} 113$ ). 